\title{
Dynamiser les apprentissages dans un contexte institutionnel
}

Eugénie Aranda

\section{CpenEdition}

\section{Journals}

Édition électronique

URL : http://journals.openedition.org/asp/4487

DOI : 10.4000/asp.4487

ISBN : 978-2-8218-0390-9

ISSN : 2108-6354

Éditeur

Groupe d'étude et de recherche en anglais de spécialité

Édition imprimée

Date de publication : 30 décembre 2002

Pagination : 89-94

ISSN : 1246-8185

Référence électronique

Eugénie Aranda, « Dynamiser les apprentissages dans un contexte institutionnel », ASp [En ligne], 37-38 | 2002, mis en ligne le 04 août 2014, consulté le 02 mai 2019. URL : http://

journals.openedition.org/asp/4487; DOI : 10.4000/asp.4487

Ce document a été généré automatiquement le 2 mai 2019

Tous droits réservés 


\title{
Dynamiser les apprentissages dans un contexte institutionnel
}

\author{
Eugénie Aranda
}

\section{NOTE DE L'ÉDITEUR}

L'auteur de cette contribution n'a pas autorisé sa publication en ligne.

\section{RÉSUMÉS}

Cet article porte sur les possibilités de dynamisation des apprentissages malgré les contraintes institutionnelles, en privilégiant l'autonomisation par le recours à des tâches appropriées, l'intégration de stratégies pertinentes et l'extension en travail sur projet.

This article deals with the necessity of promoting learner autonomy in academic contexts. This can be achieved through the implementation of relevant tasks, the development of learning strategies and the conduct of project work.

\section{INDEX}

Mots-clés : autonomisation, stratégie, tâche, travail sur projet Keywords : autonomisation, project work, strategy, task 


\section{AUTEUR}

\section{EUGÉNIE ARANDA}

Eugénie Aranda est maître de conférences à l'Université Michel de Montaigne Bordeaux 3.

Coordinatrice de projets européens Lingua, expert linguistique auprès de l'Union européenne, professeur invité à Middlebury College. 